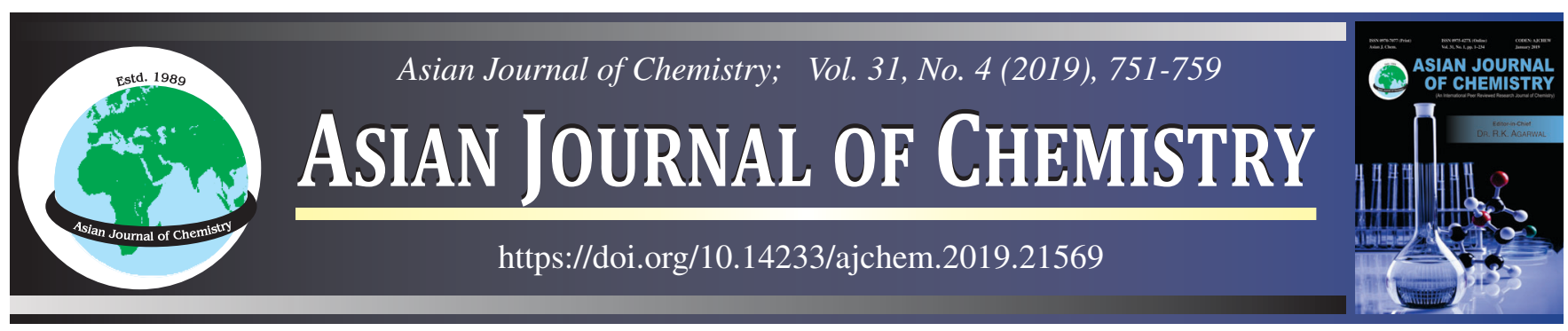

REVIEW

\title{
Self Emulsifying Drug Delivery System: A Recent Approach
}

\section{SABITRI BindhanI ${ }^{1, *}$, S. Mohapatra ${ }^{1}$ and R.K. KAR ${ }^{2}$}

${ }^{1}$ School of Pharmaceutical Sciences, Siksha 'O' Anusandhan University, Khandagiri, Bhubhaneswar-751030, India

${ }^{2}$ Department of of Pharmaceutical Sciences, Dadhichi College of Pharmacy, Cuttack-754002, India

*Corresponding author: E-mail: sabitribindhani@soa.ac.in

Received: 9 July 2018;

Accepted: 22 September 2018;

Published online: 27 February 2019;

AJC-19280

In recent years, nearly $40 \%$ newer drugs compounds are hydrophobic in nature, which is a major challenge now-a-days for oral drug delivering due to low aqueous solubility. Lipid based drug delivery system is one of the favourable approach for poorly soluble compounds which can improve the drug absorption and oral bioavailability. Due to ion-pairing with appropriate surfactant and co-surfactant the

macromolecular drug molecular oil droplet being found in the gut flow oral absorption which sufficiently stable towards lipase. Due to the | formation of emulsified drug in micron level, it can efficiently endow the oral bioavailability. Several comprehensive papers have been published in the literature illustration diverse type of lipid based formulation with recent advancements. This article is based on an exhaustive and updated review on newer technology which out line an explicit discussion on its formulations and industrial scale up.

Keywords: Lipid, Drug delivery system, Supersaturable self-emulsifying, Solidification technique, Poorly soluble drugs.

\section{INTRODUCTION}

There are number of drugs which exhibit poor gastrointestinal absorption and need more attention towards improvement on the oral bioavailability. To enhance solubility and bioavailability, many techniques are developed. To promote the apparent solubility in the gastrointestinal tract, various approaches are developed which support the drug to expose for oral administration. Several lipid based drug delivery approaches being adopted currently out of which, lipid based self-emulsifying drug delivery system (SEDDS) is most promising technology because of its potential advantage of spontaneity of emulsification and improve stabilization of bioactive materials. The rationale for this is an observable increase in the bioavailability of hydrophobic drugs when administered along with food, especially fatty meal. This is attributed to the fact that fat rich food may lead to one or more of the following such as it stimulates bile flow and pancreatic secretions, delays gastric emptying, change in gastrointestinal $\mathrm{pH}$, enhances lymphatic transport, enhances mesenteric and liver blood flow, increases intestinal wall permeability and reduces efflux activity.
Further, robust formulation advantages, easier scalability with commercial viability of various formulations such as, norvir [1], forovase [2], etc. mentioned in Table-1 have gained a considerable interest in the product development. It is an isotropic mixtures in which oil (natural or synthetic), surfactants and co-solvents or co-surfactants are incorporated to form microemulsion upon mild agitation [3,4].

The digestive motility produces agitation which improves self-emulsification and enhances the absorption of drug [5]. SEDDS gives fine emulsion from 100-300 $\mathrm{nm}$ while selfmicroemulsion drug delivery systems (SMEDDS) produces transparent microemulsion with a droplet size of less than 100 $\mathrm{nm}$. So, this system improves the rate and extent of absorption and bioavailability for lipophilic drug compound which have limited dissolution rate. So, this system improves the rate and extent of absorption and bioavailability for lipophilic drug compound which have limited dissolution rate. Admixture of three basic components such as oil, surfactants and co- surfactants/ co-solvents in a judicious manner leaded form SEDDS formulation. The compatibility of oil in both surfactants, combination of surfactants concentration and self-emulsification occur are to be considered as given in Table- 2 .

This is an open access journal, and articles are distributed under the terms of the Creative Commons Attribution-NonCommercial-ShareAlike 4.0 (CC BY-NC-SA 4.0) International License which allows readers to freely read, download, copy, distribute, print, search, or link to the full texts of its articles and to use them for any other lawful non-commercial purpose as long as the original source is duly acknowledged. 
TABLE-1

A LIST OF MARKETED PRODUCTS OF ORAL LIPID-BASED SELF-EMULSIFYING FORMULATIONS

\begin{tabular}{llll}
\hline Company & Compound & Brand name & Marketed formulation \\
\hline Novartis & Cyclosporine A/I & Neoral® & Soft gelatin capsule \\
Abbott Laboratories & Ritonavir & Norvir® & Soft gelatin capsule \\
Hoffmann-La Roche inc. & Saquinavir & Fortovase & Soft gelatin capsule \\
GlaxoSmithKline & Amprenavir & Agenerase ${ }^{\circledR}$ & Soft gelatin capsule \\
Pharmacia & Valproic acid & Convulex & Soft gelatin capsule \\
Genus & Fenofibrate & Lipirex & Hard gelatin capsule \\
Novartis & Cyclosporine A/II & Sandimmune® & Soft gelatin capsule \\
Ligand & Bexarotene & Targretin ${ }^{\circledR}$ & Soft gelatin capsule \\
Roche & Calcitriol & Rocaltrol ${ }^{\circledR}$ & Soft gelatin capsule \\
Abbott Laboratories & Cyclosporine A/III & Gengraf & Hard gelatin capsule \\
(Xanodyne Pharma) & Diclofenac potassium & Zipsor & Soft gelatin capsule \\
(Abbott) & Lopinavir and Ritonavir & Kaletra & Oral solution \\
Hoffmann-LaRoche & Saquinavir & Fortovase & Soft gelatin capsules \\
(Boehringer Ingelheim) & Tipranavir & Aptivus & Soft gelatin capsules \\
\hline
\end{tabular}

TABLE-2

LIPID FORMULATION CLASSIFICATION SYSTEM

\begin{tabular}{|c|c|c|c|c|c|c|}
\hline \multirow[b]{2}{*}{$\begin{array}{l}\text { Formulation } \\
\text { type }\end{array}$} & \multicolumn{4}{|c|}{ Components } & \multirow{2}{*}{$\begin{array}{l}\text { Particle } \\
\text { size of } \\
\text { dispersion } \\
(\mathrm{nm})\end{array}$} & \multirow[b]{2}{*}{ Characteristics } \\
\hline & $\begin{array}{c}\text { Oil (triglycerides or } \\
\text { mixed glycerides) } \\
(\% \mathrm{w} / \mathrm{w})\end{array}$ & $\begin{array}{c}\text { Surfactants } \\
(<12) \text { water } \\
\text { insoluble }\end{array}$ & $\begin{array}{c}\text { Surfactants } \\
(>11) \text { water } \\
\text { soluble } \\
\end{array}$ & $\begin{array}{l}\text { Cosolvents } \\
(\% \mathrm{w} / \mathrm{w})\end{array}$ & & \\
\hline Type I & 100 & & & & Coarse & Non-dispersing \\
\hline Type II & $40-80$ & $20-60$ & - & - & $250-2000$ & SEDDS without water-soluble components \\
\hline Type IIIA & $40-80$ & - & $20-40$ & $0-40$ & $100-250$ & $\begin{array}{l}\text { Self microemulsifying formulation with } \\
\text { water-soluble excipient }\end{array}$ \\
\hline Type IIIB & $<20$ & - & $20-50$ & $20-50$ & $50-100$ & $\begin{array}{l}\text { SMEDDS with hydrophillic components and } \\
\text { low oil content and low oil content }\end{array}$ \\
\hline Type IV & - & $0-20$ & $30-80$ & $0-50$ & $<50$ & Oil-free formulations \\
\hline
\end{tabular}

Excipients used in emulisfying drug delivery: The oils and surfactants, coupled usually with cosurfactants are the integral components of SEDDS. Depending on the relative proportion of such functional excipients, the SEDDS have been classified into four prime categories such as type I, type II, type III and type IV formulations (Table-2). Type III encompassed with the significant characterics in SEDDS and SMEDDS formulations with water soluble components. However, study of literature revealed that products are primarily based on the type III lipid-based self-emulsifying systems (i.e. containing lipids, surfactants, and/or co-surfactants) to form SEDDS/SMEDDS formulations. Due to high HLB (highly hydrophilic) value and hydrophilicity, surfactants produce fine o/w droplets by which good self emulsification and an effective absorption within the g.i. lumen can be achieved for a prolonged period of time $[6,7]$. An extensive endeavor was attempted from various literatures and patents of SEDDS formulations, which are reported to date. From the various literature search, the various articles on self-emulsifying formulations which have been summarized in Tables 3-6. Furthermore, it can be observed that a majority of the formulations are based on the liquid SEDDS technology for BCS class II and IV drugs for improving their respective oral bioavailability.

This system has widely accepted due to great performance in solubility and permeability improvement, lower the extensive first pass effect by reducing gut wall metabolism $[35,36]$. These formulations are considered as physically stable formulation which is incorporated into soft or hard gelatin capsules for oral delivery. It has been controlled intestinal permeability and $\mathrm{pH}$ at the time of absorption [37]. The mechanism of drug absorption will be improved by pre-absorptive solubilization of drug and protection of the drug from the enzymatic degradation in the gastrointestinal tracts $[38,39]$. It can be said that lipids may increase bioavailability by reducing gastric transit time, so that

TABLE-3

EXAMPLES OF SEDDS DESIGNED FOR THE ORAL DELIVERY OF LIPOPHILIC DRUGS

\begin{tabular}{lllll}
\hline List of drug & Lipid & Surfactants used & Co-surfactant & \\
\hline Gliclazide & Capryol 90 & Transcutol-HP & Tween-80 & \\
Exenatide & Cremophor EL & Labrafil 1944 & Capmul-PG 8 and propylene glycol & [9] \\
Rosuvastatin & Oleic acid & Labrafil M & Labrasol and Transcutol HP & [10] \\
Ceftriaxone & Capryol 90 & Kolliphor EL & Kolliphor PS20 & [11] \\
Probucol & Soybean oil & Labrafil M1944CS & Capmul MCM-C8 & {$[12]$} \\
Coenzyme Q10 & Labrafil M 1924 and Labrafil 2125 & Labrasol & Lauroglycol FCC and Capryol 90 & {$[13]$} \\
Docetaxel & Capryol 90 & Vitamin E TPGS & Gelucire 44/14 and Transcutol HP & {$[14]$} \\
Ontazolast & A mixture of mono- and diglycerides of oleic acid & Tween 80 & & [15] \\
Progesterone & Ethyl oleate & Tween 80 & Ethanol & {$[16]$} \\
\hline
\end{tabular}


TABLE-4

EXAMPLES OF SMEDDS DESIGNED FOR THE ORAL DELIVERY OF LIPOPHILIC DRUGS

\begin{tabular}{|c|c|c|c|c|}
\hline $\begin{array}{l}\text { Drug } \\
\text { compound }\end{array}$ & Oil & Surfactant(s) & Co-surfactant/Co-Solvent & Ref. \\
\hline Vinpocetine & Ethyl oleate & Solutol HS 15 & Transcutol P & {$[17]$} \\
\hline Acyclovir & Medium chain length triglycerides & Macrogolglycerolhydroxystearate & Polyglyceryl-3-dioleate and glycerol & [18] \\
\hline Osthole & Castor oil & Cremophor RH40 & 1,2-Propylene glycol & [19] \\
\hline Cinacalcet & Ethyl oleate & OP-10 & PEG-200 & [20] \\
\hline Simvastatin & $\begin{array}{l}\text { PEG } 300 \text { oleic glycerides, propylene glycol } \\
\text { monocaprylate, propylene glycol monolaurate }\end{array}$ & $\begin{array}{l}\text { PEG } 400 \text { caprylic/capric } \\
\text { glycerides }\end{array}$ & Polysorbate 80 & [21] \\
\hline Aciclovir & Medium chain length triglycerides & Macrogolglycerolhydroxystearate & Polyglyceryl-3-dioleate and glycerol & [22] \\
\hline
\end{tabular}

TABLE-5

EXAMPLES OF SNEDDS DESIGNED FOR THE ORAL DELIVERY OF LIPOPHILIC DRUGS

\begin{tabular}{|c|c|c|c|c|}
\hline Drug compound & Oil & Surfactant(s) & Co-surfactant/Co-Solvent & Ref. \\
\hline Glyburide & Cremophor® RH 40 & Propanediol & Miglyol ${ }^{\circledR} 812$ & {$[23]$} \\
\hline Rosuvastatin & Olive oil:garlic oil & Tween 80 & PEG 400 & [24] \\
\hline Halofantrine & Triglyceride (LLL, LML, MLM) & Maisine 35-1, Cremophor EL & Ethanol & [25] \\
\hline Darunavir & Capmul MCM C8 & Tween 80 & Transcutol P & [26] \\
\hline Tolbutamide & Oleic acid & Tween 20 & PEG 400 & [27] \\
\hline
\end{tabular}

\section{TABLE-6}

LIST OF PATENTS ON SEDDS

\begin{tabular}{lcll}
\hline \multicolumn{1}{c}{ Patent No. } & Publication date & \multicolumn{1}{c}{ Patent name } & Ref. \\
\hline US8592490B2 & $2013-11-26$ & Self-microemulsifying drug delivery systems & [28] \\
WO2012071043A1 & $2012-05-31$ & Self micro-emulsifying drug delivery system with increased bioavailabilit & [29] \\
WO2014009434A1 & $2014-01-16$ & Self-microemulsifying drug delivery system of abiraterone or abiraterone acetate & [30] \\
WO2015142307A1 & $2015-09-24$ & Self-micro/nanoemulsifying drug carrying system for oral use of rosuvastatin & [31] \\
US20050232952A1 & $2005-10-20$ & Self emulsifying drug delivery systems for poorly soluble drugs & [32] \\
US 2007/0104740 & $2007-05-10$ & Self-micro emulsifying drug delivery of HIV protease & [33] \\
WO2002007712A3 & $2002-06-13$ & Self-emulsifying drug delivery systems for extremely water-insoluble, lipophilic drugs & [34] \\
\hline
\end{tabular}

more time available for absorption [40]. In gastrointestinal region, the absorption capacity is improved due to production of intestinal mixed micelles which are stimulated by phospholipid and cholesterol [41].

The presence of lipids in gastrointestinal tract stimulates an increase in the secretion of bile salts (BS) and endogenous biliary lipids including phospholipid (PL) and cholesterol $(\mathrm{CH})$, leading to the formation of BS/PL/CH intestinal mixed micelles and an increase in the solubilization capacity of gastrointestinal tract. However, intercalation of administered (exogenous) lipids into these bile salts structures, either directly (if sufficiently polar) or secondary to digestion, leads to swelling of the micellar structures and a further increase in solubilization capacity [42]. As we know that intestinal permeability has not been a major part for lipophillic drug, but the formulations have the ability of permeation by changing biochemical barrier function and also reducing enterocyte based metabolism.

The lipidsand surfactants, coupled usually with cosurfactants, are the integral components of the SEDDS. When it is diluted, a fine emusion is formed because of lower free energy of the system [43]. It can be formulated as microemulsion in the range between 150-200 $\mathrm{nm}$ and nanoemulsion in the range of less than $100 \mathrm{~nm}$ [44]. The advantages of this system are to overcome solubility and bioavailability issues and deliver the poorly soluble drug orally by formulating it into suitable dosage form. Traditionally, it is formulated in solution form which have low stability problem, drug/excipient precipitation, handling problem and a very few dosage form further, lower drug loading and higher chances of gastrointestinal irritation, due to the presence of large quantity of surfactants (i.e. 30-60\%) [45].

Besides, the formulation of liquid SEDDS, filled in soft gelatin capsules in an industrial setup, requires programmed machinery and a colossal expenditure of resources. At times, the SEDDS also pose stability issues such as leaching of liquid oily formulations out of the capsules and problems of poor portability during handling and transport [46]. Thus, the challenges associated with liquid or semisolid drug delivery opening a new horizon for developing recent techniques in lipid based drug delivery. Supersaturable SEDDS (SS-SEDDS) and solid SEDDS (S-SEDDS) are the recent innovation to cater the drawback of the previous formulations.

Supersaturable SEDDS (SS-SEDDS): The SS-SEDDS is a thermodynamically stable formulation in which small amount of surfactant (0-20\%) and a hydrophilic polymer are incorporated to prevent precipitation and maintained a supersaturated state in vivo. When it is adminstered, an driving force for transit into and across the biological barrier is arise which prevents the precipitation and increase the thermodynamic activity of the drug [47]. It has been improved oral absorption as compared to SEDDS. Side-effect of surfactant can be minimized at the gastrointestinal region. It provides significantly high intraluminal concentration of the drug and enhances the intestinal absorption. Recently, some published articles on supersaturated self-emulsifying drug delivery system are summarized in Table-7. Supersaturable formulation of paclitaxel dutasteride was developed by using HPMC and soluplus as precipitation inhibitor [48]. 
TABLE-7

DIFFERENT SUPER SATURABLE SEDDS

\begin{tabular}{ccc}
\hline Drug & Polymer & Ref. \\
\hline Paclitaxel & HPMC & {$[48]$} \\
Krill oil & HPMC & {$[49]$} \\
Tacrolimus & Soluplus & {$[50]$} \\
Dutasteride & Soluplus & {$[51]$} \\
AMG 517 & HPMC & {$[52]$} \\
Fenofibrate & Soluplus & {$[53]$} \\
Docetaxel & HPMC & {$[54]$} \\
\hline
\end{tabular}

Solid SEDDS: Solid SEDDS are prepared by solidification of liquid/semi-solid self emulsifying ingredients into powders, granules, nanoparticles by using suitable carrier and applying different solidification technique e.g. adsorption to solid carrier, spray drying, melt-extrusion and nanoparticle technology, etc. In recent year, S-SEDDS has been introduced as an effective and alternative to conventional liquid SEDDS. After solidification, it can be further processed into solid dosage form. It is more effective than liquid self emulsifying formulation due to high stability, ease handling, more portable, very compact with high reproducibility. Solid self-emulsifying formulation of Earlotinib [55], Neusilin ${ }^{\circledR}$ US [56] and Paclitaxel [57] was developed and were found more efficient than liquid self emulsifying formulation. So different solidification technique has been developed by which liquid self emulsifying formulation is converted into solid dosage form.

Solidification technique for transforming liquid self emulsifying formulation to solid SEDDS: Solid self-emulsifying formulations are prepared by incorporating inert material(s) as a part of liquid or semi-solid self-emulsifying formulations. These formulations are prepared by following techniques:

Capsule filling technique: Both liquid and semi-solid self emulsifying formulations are encapsulated at the molten state and sealed by microspray sealing [58]. Advancement in capsule filling technology, liquid oros technology which is based on osmotic principles has been designed for delivery of peptides. When it contacts with water, it expands and drug is pumped through an orifice [59]. A primary consideration in capsule filling is the compatibility of the excipients with the capsule shell. The liquid/semi-solid lipophilic vehicles compatible with hard capsules were listed by Cole et al. [60]. The advantages of capsule filling are simplicity of manufacturing; suitability for low-dose highly potent drugs and high drug loading (up to $50 \%(\mathrm{w} / \mathrm{w})$ ) potential.

A primary consideration in capsule filling is the compatibility of the excipients with the capsule shell. The liquid/semisolid lipophilic vehicles compatible with hard capsules were listed by Tang et al. [61]. This technique is suitable for highly potent drugs and can load upto $50 \%(\mathrm{w} / \mathrm{w})$ potential.

Extrusion-Spheronization: It is one of the efficient techniques for production of pellets. The pellets are prepared by four process i.e. granulation procedure, extrusion of extrudate, spheronization of extrudate into uniform size of pellets and finally drying [61]. Manufacturing is carried out using two piece equipments called extruder- spheronizer. Extruder consists of a die through which material is forced with the help of single or twin screw, and shaped into cylinders of uniform length. Spheronizer is equipped with a bowl having fixed side walls and rapidly rotating bottom plate. The bottom plate is generally grooved to provide the equipment-particle interactions for rounding the cylindrical pellets. Extruder screen size, speed, geometry, diameter of spheronizer plate, load of extrudates on spheronizer plate and moisture content in the extrudates, are the factors affecting physical properties of pellets obtained by the process of extrusion spheronization [62].

The main advantage of this process is to produce high level of production of pellets with good flow and low friability [63].

Melt granulation: Melt granulation is also called as a thermoplastic pelletization [64]. In melt granulation, the granulating fluid is the molten material, which when mixed with other components of formulation produces agglomerated powder. It results in solidified mass upon cooling, thus completing the process ofgranulation. Melt granulation is a process in which powder agglomeration is obtained through the addition of a binder that melts or softens at relatively low temperatures. As a 'one-step' operation, melt granulation offers several advantages compared with conventional wet granulation, since the liquid addition and the subsequent drying phase are omitted. Moreover, it is also a good alternative to the use of solvent.

The main parameters that control the granulation process are impeller speed, mixing time, binder particle size and viscosity of the binder. Lipid-based excipients evaluated for melt granulation to create solid SES include lecithin, partial glycerides, or polysorbates. The melt granulation process was usually used for adsorbing SES (lipids, surfactants and drugs) onto solid neutral carriers (mainly silica and magnesium aluminometa silicate) [65].

Essentially, this technique involves the preparation of a formulation by mixing lipids, surfactants, drug, solid carriers and solubilization of the mixture before spray drying. The solubilized liquid formulation is then atomized into a spray of droplets. The droplets are introduced into a drying chamber, where the volatile phase (e.g. the water contained in an emulsion) evaporates, forming dry particles under controlled temperature and airflow conditions. Such particles can be further prepared into tablets or capsules [66]. The atomizer, temperature, the most suitable airflow pattern and the drying chamber design are selected according to the drying characteristics of product and powder specification.

Spray drying: Industrially, it is a very useful approach in which liquid self emulsifying formulation is transformed into solid self emulsifying formulation. Such systems not only improve the formulation stability, but subsequently augment the biopharmaceutical performance, too. Solid hydrophilic polymers such as microcrystalline cellulose (MCC), hydroxypropylmethylcellulose (HPMC), hydroxypropyl cellulose (HPC) and hydrophobic polymer (e.g., crosspovidone) are commonly used as carriers for preparing the spray-dried SEsystems.

Another example of the composition prepared by spray drying is nimodipine SMEDDS, which uses dextran as a solid carrier. Emulsion containing nimodipine, dextran, cremophor RH40 and labrasol was spray dried to produce solid SMEDDS. The SMEDDS prepared by the method of spray drying has been disclosed in the patent EP2101729A1 [67]. The aqueous solution of drug (candesartan cilexetil, celecoxib, sirolimus, lercanidipine hydrochloride or eprosartan mesylate), poly- 
oxyethylene sorbitan fatty acid ester, fatty acid ester, oil, and a solid support, e.g., polyvinylpyrrolidone (PVP) or lactose was prepared. The resulting solution was then spray dried to prepare a SMEDDS [67].

Lyophilization: Lyophilization allows sublimation of the frozen aqueous phase present in liquid SE formulations at reduced temperature and pressure to obtain the powder, which on reconstitution with aqueous phase produces a fine microemulsion/nanoemulsion. Cryoprotectants such as mannitol, dextrose, lactose and trehalose are generally added during lyophilization, and act as bulk formers and help in the formation of a flowable dry powder.

The lyophilized SEDDS have the advantages of better drug stability, enhanced efficacy and improved patient compliance. Lyophilization can be successfully applied to drugs that are sensitive to temperature, oxygen and/or air. Patent EP2101729A1 describes the solid SMEDDS prepared by lyophilization. The concentrate containing a drug, emulsifier, co-emulsifier, and oil is mixed with the aqueous solution of solid support, which is then solidified by the process of lyophilization [68].

Adsorption on solid support: In this process, solid carrier plays an important role to adsorb large quantity of self emulsifying formulation and converted it into free flowing powder [69]. Calcium silicate, silicon dioxide, magnesuim alumino metasilicate, carbon nanotubes, lactose, fumed silica under trade name Aerosil 200, 300 and R972, mesoporous silica gel under trade name Syloid XDP, Syloid 244FP, micronized amorphous silica under trade name Sylysia and magnesium alumino metasilicate under trade name Neusilin, silicon dioxide has been used recently [70]. Recent literature reflects for the application of silicates such as silicon dioxide (e.g. Aerosil), aluminum silicate and its derivatives (e.g. Sylysia and Neusilin), calcium silicate (e.g. Florite and Hubersob), micronized porous silica gel (e.g. Syloid), and precipitated silica (e.g. Neosyl) as the porous carriers for adsorption of the liquid oily formulations [10]. Kallakunta et al. [71] formulated the solid SE powder of lercanidipine and reported the effectiveness of Sylysia and Neusilin in improving the micromeritics and formulation characteristics of SE liquid formulations. Beg et al. [72] reported 3to 3.5-fold enhancement in the oral bioavailability employing solid self-emulsifying granules of ondansetron using Sylysia 350 and Neusilin US2 as the solidifying agents.

The liquid formulation consisting of poorly soluble active agent, water soluble non-ionic water miscible surfactant, a waterimmiscible lipid-soluble surfactant and a fatty acid mono- or di-glyceride was adsorbed onto the porous particulates. The active agent includes CoQ10, vitamin $\mathrm{A}$, vitamin $\mathrm{D}$, vitamin $\mathrm{E}$, vitamin $\mathrm{K}$, lycopene, lutein, resveratrol and ginseng extract or their mixtures. The porous particulates were selected from the group consisting of calcium hydrogen phosphate, aluminometasilicate, and silicon dioxide [73].

\section{Recent advancements in sedds}

Self-emulsifying formulations take different forms depending upon the purpose and principle of the drug delivery system. The developments in the solid self-emulsifying technologies are discussed below:

Self-emulsifying controlled-release (CR) tablet: This tablet (SECRET) is a newer technological improvement in the area of S-SEDDS for achieving controlled drug release profile. SECRET is a patented proprietary platform technology developed by AlphaRx Inc. (San Diego, California, United States), where liquid SE formulations are converted into tablets by adsorbing onto the surface of rate-controlling polymers such as HPC, HPMC, etc. [74].

An eutectic based self-microemulsifying tablet of coenzyme Q10 was prepared by Nazzal and Khan [75]. They had evaluated effect of solid carrier i.e. colloidal silica and magnesium stearate and compression force on hardness and dissolution of controlled release tablet of coenzyme Q10. It was also found that the solid carriers and compression force were in optimum level [76]. Tacrolimus was developed as gastroretentive SR tablet by using polyethylene oxide, chitosan, poly(vinyl pyrollidone) and mannitol as solid carrier. It was proved that this tablet enhance the oral bioavailability of tacrolimus [76]. The SE tablets of carvedilol containing HPMC, MCC and aeroperl as tableting excipients have been reported to result in substantial augmentation of in vitro drug uptake in HCT-116 cell lines plausibly due to the inhibition of P-gp efflux [77]. Nekkanti et al. [78] demonstrated the potential of solid SMEDDS tablets of candesartan cilexetil in significant enhancing the rate and extent of drug dissolution and consequently, the oral bioavailability [79].

Self-emulsifying sustained-release (SR) pellets: It is a suitable dosage form for sustained release due to their smooth spherical shape and narrow size distribution. It reduces intrasubject and inter-subject variability of plasma profiles and G.I. irritation without affecting drug bioavailability [79]. A selfemulsifying controlled release pellets were prepared by Serratoni et al. [80]. They had incorporated self-emulsifying excipients to prepare self-emulsifying pellets and coated the pellets with water insoluble polymer which retard the rate of drug release. They had concluded that due to presence of polymer film, the rate of drug release was controlled which was not affected by excipients. Another report on sustained release matrix pellets in which gelucire 54/02 and gelucire 70/02 were used [81].

Self-emulsifying SR microspheres: Quasi-emulsion solvent diffusion method of spherical crystallization technique is used for preparing self emulsifying sustained release microsphere. A sustained release microsphere was prepared by using zedoary turmeric oil (ZTO) as oil phase which exhibited potent pharmacological actions. The ratio of hydroxypropyl methyl cellulose acetate succinate to Aerosil 200 was used to control the release behaviour of ZTO in the formulation. Finally, it was concluded that such microspheres had shown maximum bioiavailability as compared to conventional formulation [82].

Self-emulsifying nanoparticles: These are prepared by solvent injection technique in which liquid formulation is injected dropwise into a stirred non-solvent. Then they are filtered and dried. An another technique to prepare nanoparticles is sonication emulsion diffusion evaporation technique in which the mixture of polylactide co-glycolide (PLGA) and O-carboxymethyl chitosan (O-CMC) were used. The nanoparticles provide controlled release profile of drug delivery and improved stability in gastric fluid, along with enhanced oral bioavailability. Such formulations produce o/w microemulsions in situ on coming in contact with GI fluids. 5-Fluorouracil and paclitaxel are 
some of the examples of drugs that have recently been reported to be constituted as SE nanoparticulate systems for exploring their oral bioavailability enhancement. Holmberg and Siekmann [83] prepared the SE nanoparticles of 5-fluorouracil employing PLGA/O-carboxymethyl chitosan by solvent evaporation technique and observed significantly enhanced cellular uptake of drug through the intestinal lymphatic pathways, lower cytotoxicity, and remarkable reduction in the gliomas as evident from MTT assay, TUNNEL technique and immunohistochemical staining. The SE nanoparticles of paclitaxel by emulsion solvent evaporation using chitosan and glyceryl monooleate were observed to exhibit fourfold increase in the cellular uptake of drug and significantly lower cytotoxicity through MTT assay [84].

An eutectic based selfnano-emulsifying formulation was prepared by Nazzal et al. [85] and studied the dug release mechanism by turbidimetric analysis and droplet size analysis. They had shown that the formulation can overcome the low solubility and irreversible precipitation formed in conventional formulation. Bakerman et al. [86] had prepared cyclosporin lipid nanoparticle by using phospholipid, span 80 , Tween 80 , tricaprin and cremophor RH 40. The conclusion was that nanoparticles had shown maximum oral bioavailability. In 2010, Nepal et al. [87] had prepared nanoemulsion in which the surfactants and co-surfactants was mixed at the ratio of 1:4 which provide a sufficient mechanical barrier to coalescence oil droplets. Koynova and Tihova [88] had prepared self-nanoemulsifying formulation by using nanosized SE lipid vesicles as carriers. They had suggested that it can be a good alternative for formulation which overcome the stability, sterilization problem and nonreproducibility between batches.

Self emulsifying beads (non-oral): These are prepared by incorporating very small amount of excipients into solid dosage form. Patil and Paradkar [89] had utilized solvent evaporation method for loading of self emulsifying liquid into micro channels of porous polystyrene beads. It was found that porous polystyrene beads was considered as potential carrier for solidification. Due to its uniform bead size and pore architecture, the loading efficiency and in vitro drug release was maximum. Floating alginate self-emulsifying beads of tetrahydrocurcumin by using different propertion of sodium alginate, calcium chloride and water soluble pore former. It was concluded that gastric residence time was increased due to floating properties [90].

SE suppository formulations (non-oral): The drugs which cannot reach the maximum theraputic concentration by oral route, these drugs are formulated by incorporating selfemulsifying excipients into selfemulsifyingsuppositories [91]. Glycyrrhizin, for the treatment of chronic hepatic diseases cannot achieve maximum theraputic level orally. But when it is formulated as vaginal or rectal SE suppositories by using a mixture of a C6-C18 fatty acid glycerol ester and a C6-C18 fatth acid macrogol ester. It was found that the maximum therapeutic concentration was achieved [92].

SE mucoadhesive systems: These formulations majorly contain drug dissolved within the lipidic excipients along with mucoadhesive polymers such as acacia, tragacanth and lecithin, which undergo emulsification on contact with mucosal surface to produce fine o/w microemulsions/ nanoemulsions. The SE mucoadhesive formulations containing glyceryl monostearate and cremophor RH40, along with mucoadhesive polymers such as acacia and lecithin, have been reported for augmenting oral bioavailability of cannabnoids, ascribable to increase in GI residence time of the formulation [92].

Self-emulsifying transdermal systems (non-oral): The potential of SEDDS for transdermal delivery has not yet been fully explored. However, it has been proposed that the SE formulations can enable the transdermal delivery of hydrolyzable drugs undergoing extensive hepatic first-pass effect. These systems undergo phase inversion on when attached with excretatory fluid of the skin to produce supersaturated system This phenomenon of inversion generates the driving force, (i.e. flux) for transdermal delivery of drugs through stratum corneum to enhance its systemic availability [93]. Of late, the method of preparation of self-emulsifying matrix systems containing long-chain unsaturated fatty acids and fatty alcohols for transdermal delivery of flubiprofen has been patented for its improved therapeutic performance. In another report nearly 1.2-fold increase in the flux across rat skin for SE transdermal systems of indomethacin was observed over conventional microemulsions [94].

Self-emulsifying ocular systems (non-oral): Recently, the SEDDS have demonstrated their immense utility for ocular delivery system for the treatment of pathological disorders such as choroidal neovascularization, macular degeneration, edema, uveitis, diabetic retinopathy, etc. A formulation of ultrafine and stable SE oily formulations of NSAIDs containing Polyox-40 castor oil, Lumulse GRH40 and Tween 80 has been patented for opthalmic application [95]. The SE formulation of cyclosporine and rapamycin containing phosphatidylcholine, PEG 400 and Nikkol HCO-35 exhibited 10-fold more effective as compared with opthalmic preparation for the treatment of neovascularization [96].

Self-double emulsifying drug delivery systems (SDEDDS): SEDDS is applied for the solubility and oral absorption for improvement. Self-double emulsifying drug delivery system (SDEDDS) is applied to drug having high solubility and low permeability. After dissolution, permeability is a major and important factor which affects the oral absorption of drug. So $\mathrm{w} / \mathrm{o} / \mathrm{w}$ and o/w/o are double emulsions in which drugs are encapsulated at the innermost phase to release the drug for prolonged time. Wang et al. [97] had developed topical hydrogel which is vitamin C loaded loaded self double emulsifying formulation which is used topically. Industrially, it is used limited due to its instability. But Hu et al. [98] had developed a novel SDEDDS preparation by formulating hydrophillic surfactants with w/o emulsion. They had concluded that SDEDDS of a peptidomimetic drug can be delivered. Another formulation was prepared to improve EPGCG photostability which possess sustained release behaviour. Epigallocatechin 3-gallate (EGCG) and $\alpha$-lipoic acid was used for preparing SDEDDS formulation [99]. Another new formulation was investigated named as o/o/w double emulsion which is automatically formed after dilution in aqueous phase. Drugs are mainly encapsulated in the innermost oil phase [100].

Eutectic based self-emulsifying formulations: In this kind of drug delivery system, highly lipophilic drug can be 
melted at body temperature by inclusion of an eutectic agent. Sometimes, the eutectic agent can be a lipid phase that does not melt at body temperature leaving the drug alone in the molten state at or below body temperature. The molten drug is then emulsified by surfactant and cosurfactant. Nazzal and Khan [74] reported improved drug stability and superior physiochemical performance for eutectic SNEDDS of a coenzyme Q10 containing mixture of volatile oils such as menthe oil, anise oil, peppermint oil, and spearmint oil using surfactants such as Cremophor 35RH and Capmul MCM

Charged self-emulsifying formulations: Enhancement of bioavailability of drug through developments in self-emulsifying formulations is based on increasing drug solubility, modifying biochemical and physical barrier function and promoting lymphatic drug absorption, As GI absorptive cells carry a negative charge and charge carried by formulation may affect the absorption of drug. Positively charged self-emulsifying compositions exhibit enhanced bioavailability than negatively charged compositions. One example of positively charged SEDDS is ibuprofen SEDDS prepared from ethyl oleate as an oil, oleyl amine as a cationic lipid, and Tween 80:Span 80 (3:1) as surfactants. This system showed highest absorption than negatively charged SEDDS and pure drug in in vitro GI absorption studies [101].

Application of SEDDS in plant and herbal drugs: Recently, research has been focused on development and utilizing herbal drugs in SEDDS preparation. Herbal drugs are widely used in the east region, which can be used in allregions. SEDDS is a thermodynamically stable formulation in which herbal drugs which has hydrophobic properties and poor distribution can be incorporated. This system can spontaneously form oil in water micro or nano-emulsion which can overcome the solubility, bioavailability and instabilty problem of a poorly soluble herbal drugs [102].

In present research, by utilization of herbal drugs, Yen et al. [103] and Cui et al. [104] had developed polymeric nanoparticles, Sierant et al. [105] had developed nanocapsules, Zhou et al. [106] and Khan et al. [107] had developed liposomes, Li et al. [108] had developed solid lipid nanoparticles, Wei et al. [109] had developed nanoemulsion and enhanced solubility, bioavailability, pharmacological activity, stability, tissue macrophages distribution, sustained delivery of drugs and protection from physical and chemical degradation. Cai et al. [110] had demonstrated that by using herbal drugs self emulsifyingdrug delivery system can be more useful and effective. So for this system plant drugs are selected whose oral absorption can be enhanced by using self emulsifying excipients. Before proceeding to the formulation, preformulation studies of herbal drugs and with excipients should be done. In this review, present research emphasize on the development of SEDDS, effect of excipents and poorly water soluble phytoconstituents [111].

\section{Conclusion}

SEDDS is considered as best approach for the formulation of drug compounds with poor aqueous solubility. Still this system is not very widespread due to its physical and chemical stability issues. In this review, various formulations have been developed which can reduce the stability issues. Oral SET, self nanoemulsifying and self microemulsifying system have offered advantages in drug delivery. Also this review emphasizes on some new solidification technique which convert the liquid or semi-solid formulation into powder, granule which can be further processed into different dosage form like compressed tablet, capsules, pellets, etc.

\section{CONFLICT OF INTEREST}

The authors declare that there is no conflict of interests regarding the publication of this article.

\section{REFERENCES}

1. M. Grove, A. Müllertz, J.L. Nielsen and G.P. Pedersen, Eur. J. Pharm. Sci., 28, 233 (2006); https://doi.org/10.1016/j.ejps.2006.02.005.

2. M.E. Perlman, S.B. Murdande, M.J. Gumkowski, T.S. Shah, C.M. Rodricks, J. Thornton-Manning, D. Freel and L.C. Erhart, Int. J. Pharm., 351, 15 (2008); https://doi.org/10.1016/j.ijpharm.2007.09.015.

3. D.Q.M. Craig, H.S.R. Lievens, K.G. Pitt and D.E. Storey, Int. J. Pharm., 96, 147 (1993);

https://doi.org/10.1016/0378-5173(93)90222-2.

4. H. Toguchi, Y. Ogawa, K. Iga, T. Yashiki and T. Shimamoto, Chem. Pharm. Bull. (Tokyo), 38, 2792 (1990);

https://doi.org/10.1248/cpb.38.2792.

5. S. Akula, A.K. Gurram and S.R. Devireddy, Int. Sch. Res. Notices, 2014, 964051 (2014); https://doi.org/10.1155/2014/964051.

6. A.T.M. Serajuddin, D. Mufson, D.F. Bernstein, P.-C. Sheen and M.A. Augustine, J. Pharm. Sci., 77, 414 (1988); https://doi.org/10.1002/jps.2600770512.

7. N.H. Shah, M.T. Carvajal, C.I. Patel, M.H. Infeld and A.W. Malick, Int. J. Pharm., 106, 15 (1994); https://doi.org/10.1016/0378-5173(94)90271-2.

8. T.S. Nipun and S.M. Ashraful Islam, Saudi Pharm. J., 22, 343 (2014); https://doi.org/10.1016/j.jsps.2013.06.001.

9. C. Menzel, T. Holzeisen, F. Laffleur, S. Zaichik, M. Abdulkarim, M. Gumbleton and A. Bernkop-Schnürch, J. Control. Rel., 277, 165 (2018); https://doi.org/10.1016/j.jconrel.2018.03.018.

10. H.Y. Karasulu, E. Gundogdu, U.O. Turk, T. Turgay, S. Apaydin, I.Y. Simsir, C. Yilmaz and E. Karasulu, Curr. Drug Deliv., 15, 1072 (2018); https://doi.org/10.2174/1567201815666180226114545.

11. T. Kauss, A. Gaubert, L. Tabaran, G. Tonelli, T. Phoeung, M.H. Langlois, N. White, A. Cartwright, M. Gomes and K. Gaudin, Int. J. Pharm., 536, 283 (2018); https://doi.org/10.1016/j.ijpharm.2017.11.067.

12. A. Zaghloul, I. Khattab, A. Nada and S. Al-Saidan, Pharmazie, 63, 654 (2008); https://doi.org/10.1691/ph.2008.8098

13. P. Balakrishnan, B.J. Lee, D.H. Oh, J.O. Kim, Y.I. Lee, D.D. Kim, J.P. Jee, Y.-B. Lee, J.S. Woo, C.S. Yong and H.-G. Choi, Int. J. Pharm., 374, 66 (2009); https://doi.org/10.1016/j.ijpharm.2009.03.008

14. G.R. Valicherla, K.M. Dave, A.A. Syed, M. Riyazuddin, A.P. Gupta, A. Singh, K. Wahajuddin, K. Mitra, D. Datta and J.R. Gayen, Sci. Rep., 6, 26895 (2016); https://doi.org/10.1038/srep26895.

15. D.J. Hauss, S.E. Fogal, J.V. Ficorilli, C.A. Price, T. Roy, A.A. Jayaraj and J.J. Keirns, J. Pharm. Sci., 87, 164 (1998); https://doi.org/10.1021/js970300n.

16. W.N. Charman, Lipophillic Transport of Drugs, CRC Press: Boca Raton, FL, p. 113 (1992).

17. S.X. Cui, S.F. Nie, L. Li, C.G. Wang, W.S. Pan and J.P. Sun, Drug Dev. Ind. Pharm., 35, 603 (2009); https://doi.org/10.1080/03639040802488089.

18. L. Djekic, J. Jankovic, A. Raskovic and M. Primorac, Eur. J. Pharm. Sci., 121, 287 (2018); https://doi.org/10.1016/j.ejps.2018.06.005

19. C. Sun, Y. Gui, R. Hu, J. Chen, B. Wang, Y. Guo, W. Lu, X. Nie, Q. Shen, S. Gao and W. Fang, AAPS PharmSciTech, 19, 2301 (2018); https://doi.org/10.1208/s12249-018-1067-3. 
20. M. Cao, X. Xue, X. Pei, Y. Qian, L. Liu, L. Ren and G. Chen, Drug Dev. Ind. Pharm., 44, 969 (2018); https://doi.org/10.1080/03639045.2018.1425428.

21. Z. Cetkovic, S. Cvijic and D. Vasiljevic, Drug Dev. Ind. Pharm., 44, 849 (2018); https://doi.org/10.1080/03639045.2017.1414835.

22. L. Djekic, J. Jankovic, B. Ėalija and M. Primorac, Int. J. Pharm., 528, 372 (2017); https://doi.org/10.1016/j.ijpharm.2017.06.028.

23. H. Liu, K. Shang, W. Liu, D. Leng, R. Li, Y. Kong and T. Zhang, J. Microencapsul., 31, 277 (2014); https://doi.org/10.3109/02652048.2013.843598.

24. H.A. Abo Enin, Drug Dev. Ind. Pharm., 41, 1047 (2015); https://doi.org/10.3109/03639045.2014.983113.

25. R. Holm, C.J.H. Porter, G.A. Edwards, A. Müllertz, H.G. Kristensen and W.N. Charman, Eur. J. Pharm. Sci., 20, 91 (2003); https://doi.org/10.1016/S0928-0987(03)00174-X.

26. S. Inugala, B.B. Eedara, S. Sunkavalli, R. Dhurke, P. Kandadi, R. Jukanti and S. Bandari, Eur. J. Pharm. Sci., 74, 1 (2015); https://doi.org/10.1016/j.ejps.2015.03.024.

27. D. Pandita, N. Kumari and V. Lather, Pharm. Nanotechnol., 5, 285 (2017); https://doi.org/10.2174/2211738505666170915154920.

28. I. Legen, J. Kerc and P. Jurkovic, Self-Micro Emulsifying Drug Delivery Systems, US Patent 8592490B2 (2013).

29. E. Hassan, Self Microemulsifying Drug Delivery System with Increased Bioavailability, World Patent WO 2012071043A1 (2012).

30. I. Legen, L. Peternel, S.M. Novak, M. Homar, P.T. Rozman and U. Klancar, Self-Microemulsifying Drug Delivery System of Abiraterone or Abiraterone Acetate, World Patent WO 2014009434A1 (2014).

31. H.Y. Karasulu, S. Apaydin, E. Gundogdu, S.I. Yildirim, U.O. Turk, E. Karasulu, C. Yilmaz and T. Turgay, Self-Micro/Nanoemulsifying Drug Carrying System for Oral Use of Rosuvastatin, World Patent WO 2015142307A1 (2015).

32. G. Lambert, A. Razafindratsita, J. Sebastien, G. Shicheng, Y.N. Gursoy and S. Benita, Self Emulsifying Drug Delivery Systems for Poorly Soluble Drugs, US Patent 20050232952A1 (2015).

33. J.F. Voorspoels, Self-microemulsifying Drug Delivery of HIV Protease, US Patent 2007/0104740 (2007).

34. P. Gao, W. Morozowich and N. Shenoy, Self-Emulsifying Drug Delivery Systems for Extremely Water-Insoluble, Lipophilic Drugs, WO 2002007712A3 (2002).

35. K. Kohli, S. Chopra, D. Dhar, S. Arora and R.K. Khar, Drug Discov. Today, 15, 958 (2010); https://doi.org/10.1016/j.drudis.2010.08.007.

36. B. Singh, S. Beg, R.K. Khurana, P.S. Sandhu, R. Kaur and O.P. Katare, Crit. Rev. Ther. Drug Carrier Syst., 31, 121 (2014); https://doi.org/10.1615/CritRevTherDrugCarrierSyst.2014008502.

37. S. Gupta, S. Chavhan and K.K. Sawant, Colloids Surf. A Physicochem. Eng. Asp., 392, 145 (2011); https://doi.org/10.1016/j.colsurfa.2011.09.048.

38. D.J. Hauss, Drugs and Pharmaceutical Sciences, Informa Healthcare: NC, USA, vol. 170, pp. 1-339 (2007).

39. C.M. O'Driscoll, Eur. J. Pharm. Sci., 15, 405 (2002); https://doi.org/10.1016/S0928-0987(02)00051-9.

40. Y. Ito, T. Kusawake, M. Ishida, R. Tawa, N. Shibata and K. Takada, J. Control. Rel., 105, 23 (2005); https://doi.org/10.1016/j.jconrel.2005.03.017.

41. G. Verreck and M.E. Brewster, J. Melt Extrusion, 97, 85 (2004).

42. J. Bamba, G. Cavé, Y. Bensouda, P. Tchoreloff, F. Puisieux and G. Couarraze, Drug Dev. Ind. Pharm., 21, 1749 (1995); https://doi.org/10.3109/03639049509069262.

43. M. Grove and A. Müllertz, Liquid Self-Microemulsifying Drug Delivery Systems, Informa Healthcare, p. 107 (2007).

44. E. Rudnic, J. McCarty, G. Belendiuk, B. Burnside, C. McGuinness and K. Belendiuk, Emulsified Drug Delivery System, US Patent 5897876 (1999).

45. B. Singh, S. Bandopadhyay, R. Kapil, R. Singh and O.P. Katare, Crit. Rev. Ther. Drug Carrier Syst., 26, 427 (2009); https://doi.org/10.1615/CritRevTherDrugCarrierSyst.v26.i5.10.

46. A. Singh, V. Singh, D. Juyal and G. Rawat, Asian J. Pharm., 9, 13 (2015).

47. N.D. Patel, K.V. Patel, A.K. Shukla and P.K. Sheat, Int. J. Pharm. Biol. Arch., 2, 621 (2011).

48. P. Gao, B.D. Rush, W.P. Pfund, T. Huang, J.M. Bauer, W. Morozowich, M.S. Kuo and M.J. Hageman, J. Pharm. Sci., 92, 2386 (2003); https://doi.org/10.1002/jps.10511.
49. Y. Seto, C. Morizane, K. Ueno, H. Sato and S. Onoue, J. Agric. Food Chem., 66, 5352 (2018); https://doi.org/10.1021/acs.jafc.8b00693.

50. M.S. Lee, C.-M. Su, J.-C. Yeh, P.-R. Wu, T.-Y. Tsai and S.-L. Lou, Int. J. Nanomedicine, 11, 4583 (2016); https://doi.org/10.2147/IJN.S112415.

51. D.H. Lee, D.W. Yeom, Y.S. Song, H.R. Cho, Y.S. Choi, M.J. Kang and Y.W. Choi, Int. J. Pharm., 478, 341 (2015); https://doi.org/10.1016/j.ijpharm.2014.11.060.

52. P. Gao, A. Akrami, F. Alvarez, J. Hu, L. Li, C. Ma and S. Surapaneni, J. Pharm. Sci., 98, 516 (2009); https://doi.org/10.1002/ips.21451.

53. G. Quan, B. Niu, V. Singh, Y. Zhou, C.Y. Wu, X. Pan and C. Wu, Int. J. Nanomedicine, 12, 8801 (2017); https://doi.org/10.2147/IJN.S149717.

54. Y. Chen, C. Chen, J. Zheng, Z. Chen, Q. Shi and H. Liu, Biol. Pharm. Bull., 34, 278 (2011); https://doi.org/10.1248/bpb.34.278.

55. D.H. Truong, T.H. Tran, T. Ramasamy, J.Y. Choi, H.H. Lee, C. Moon, H.G. Choi, C.S. Yong and J.O. Kim, AAPS PharmSciTech, 17, 466 (2016); https://doi.org/10.1208/s12249-015-0370-5.

56. S.G. Gumaste, B.O.S. Freire and A.T.M. Serajuddin, Eur. J. Pharm. Sci., 110, 124 (2017); https://doi.org/10.1016/j.ejps.2017.02.022.

57. H.Y. Cho, J.H. Kang, L. Ngo, P. Tran and Y.B. Lee, J. Nanomater. Volume 2016, Article ID 3642418 (2016); https://doi.org/10.1155/2016/3642418.

58. S. Dokania and A.K. Joshi, Drug Deliv., 22, 675 (2015); https://doi.org/10.3109/10717544.2014.896058.

59. L. Dong, A Novel Osmotic Delivery System: L-OROS SOFTCAP. Proceedings of the International Symposium on Controlled Release of Bioactive Materials, July, Paris (2000).

60. E.T. Cole, D. Cade and H. Benameur, Adv. Drug Deliv., 60, 747 (2008); https://doi.org/10.1016/j.addr.2007.09.009.

61. B. Tang, G. Cheng, J.C. Gu and C.H. Xu, Drug Discov. Today, 13, 606 (2008); https://doi.org/10.1016/j.drudis.2008.04.006.

62. H. Michie, F. Podczeck and J.M. Newton, Int. J. Pharm., 434, 175 (2012); https://doi.org/10.1016/j.ijpharm.2012.05.050.

63. S.N. Politis and D.M. Rekkas, Recent Pat. Drug Deliv. Formul., 5, 61 (2011); https://doi.org/10.2174/187221111794109493.

64. V. Jannin, J. Musakhanian and D. Marchaud, Adv. Drug Deliv. Rev., 60, 734 (2008); https://doi.org/10.1016/j.addr.2007.09.006.

65. M.K. Gupta, D. Goldman, R.H. Bogner and Y.C. Tseng, Pharm. Dev. Technol., 6, 563 (2001): https://doi.org/10.1081/PDT-120000294.

66. T. Yi, J. Wan, H. Xu and X. Yang, Eur. J. Pharm. Biopharm., 70, 439 (2008); https://doi.org/10.1016/j.ejpb.2008.05.001

67. P. Jurkovic, J. Kerc and I. Legen, Self-Emulsifying Drug Delivery System, European Patent EP2101729A1 (2009).

68. C. Fabio and C. Elisabetta, Pharmaceutical Composition Comprising a Water/Oil/Water Double Microemulsion Incorporated in a Solid Support. World Patent WO 2003/013421 (2003).

69. N. Venkatesan, J. Yoshimitsu, Y. Ito, N. Shibata and K. Takada, Biomaterials, 26, 7154 (2005); https://doi.org/10.1016/j.biomaterials.2005.05.012.

70. A. Tan, S. Rao and C.A. Prestidge, Pharm. Res., 30, 2993 (2013); https://doi.org/10.1007/s11095-013-1107-3.

71. V.R. Kallakunta, S. Bandari, R. Jukanti and P.R. Veerareddy, Powder Technol., 221, 375 (2012); https://doi.org/10.1016/j.powtec.2012.01.032.

72. S. Beg, S. Swain, H.P. Singh, C.N. Patra and M.E. Rao, AAPS PharmSciTech, 13, 1416 (2012); https://doi.org/10.1208/s12249-012-9865-5.

73. L.C. Dong, S. Li and C. Pollock-Dove, Stabilized Solubility-Enhanced Formulations for Oral Delivery, US Patent 20100247632A1 (2010).

74. J. Schwarz, Solid Self-Emulsifying Dosage Form for Improved Delivery of Poorly Soluble Hydrophobic Compounds and the Process for Preparation thereof, US Patent 2003/0072798 (2003).

75. S. Nazzal and M.A. Khan, Int. J. Pharm., 315, 110 (2006); https://doi.org/10.1016/j.ijpharm.2006.02.019. 
76. Y.P. Wang, Y. Gan and X.X. Zhang, Acta Pharmacol. Sin., 32, 1294 (2011); https://doi.org/10.1038/aps.2011.90.

77. E.A. Mahmoud, E.R. Bendas and M.I. Mohamed, AAPS PharmSciTech, 10, 183 (2009); https://doi.org/10.1208/s12249-009-9192-7.

78. V. Nekkanti, P. Karatgi, R. Prabhu and R. Pillai, AAPS PharmSciTech, 11, 9 (2010); https://doi.org/10.1208/s12249-009-9347-6.

79. R. Gandhi, C.L. Kaul and R. Panchangnula, Pharm. Sci. Technol. Today, 4, 160 (1999); https://doi.org/10.1016/S1461-5347(99)00136-4.

80. M. Serratoni, M. Newton, S. Booth and A. Clarke, Eur. J. Pharm. Biopharm., 65, 94 (2007); https://doi.org/10.1016/j.ejpb.2006.07.011.

81. J. Hamdani, A.J. Moës and K. Amighi, Int. J. Pharm., 260, 47 (2003); https://doi.org/10.1016/S0378-5173(03)00229-1.

82. J. You, F.D. Cui, X. Han, Y.S. Wang, L. Yang, Y.W. Yu and Q.P. Li, Colloids Surf. B Biointerfaces, 48, 35 (2006); https://doi.org/10.1016/i.colsurfb.2005.12.011.

83. C. Holmberg and B. Siekmann, Self-Emulsifying Drug Delivery System, US Patent US 7736666B2 (2010).

84. G. Shlieout, B. Boedecker, S. Schaefer, B. Thumbeck and P. Gregory, Pharmaceutical Compositions of Lipase-Containing Products, In Particular of Pancreation, US Patent 2005/0250817 (2005)

85. S. Nazzal, I.I. Smalyukh, O.D. Lavrentovich and M.A. Khan, Int. J. Pharm., 235, 247 (2002); https://doi.org/10.1016/S0378-5173(02)00003-0.

86. T. Bekerman, J. Golenser and A. Domb, J. Pharm. Sci., 93, 1264 (2004); https://doi.org/10.1002/jps.20057.

87. P.R. Nepal, H.K. Han and H.K. Choi, Eur. J. Pharm. Sci., 39, 224 (2010); https://doi.org/10.1016/j.ejps.2009.12.004.

88. R. Koynova and M. Tihova, Biochim. Biophys. Acta, 1798, 646 (2010); https://doi.org/10.1016/j.bbamem.2009.12.022.

89. P. Patil and A. Paradkar, AAPS PharmSciTech., 7, E199 (2006); https://doi.org/10.1208/pt070128.

90. A. Sookkasem, S. Chatpun, S. Yuenyongsawad and R. Wiwattanapatapee, J. Drug Deliv. Sci. Technol., 29, 159 (2015); https://doi.org/10.1016/j.jddst.2015.07.005.

91. J.Y. Kim and Y.S. Ku, Int. J. Pharm., 194, 81 (2000); https://doi.org/10.1016/S0378-5173(99)00367-1.

92. K. Takada and M. Murakami. Glycyrrhizin Preparations for Transmucosal Absorption, US Patent 6890547 (2005)

93. B. Whittle and G. Guy, GW Pharma Ltd., Mucoadhesive Pharmaceutical Formulations. World Patent WO 02/064109A2 (2002).

94. G.M. El Maghraby, Colloids Surf. B Biointerfaces, 75, 595 (2010); https://doi.org/10.1016/j.colsurfb.2009.10.003.
95. Z. Yu and S. Huth, Stable Ophthalmic Oil-in-Water Emulsions with Sodium Hyaluronate for Alleviating Dry Eye, United States Patent US 2007/0036829 (2007)

96. P.J. Dor, S. Mudumba, T. Nivaggioli and D.A. Weber, Formulations for Ocular Treatment, United States Patent US 2006/0182771 (2006).

97. Q. Wang, H. Zhang, J. Huang, N. Xia, T. Li and Q. Xia, J. Microencapsul., 35, 90 (2018); https://doi.org/10.1080/02652048.2018.1425752.

98. C. Hu, G. Zhao, Q. Xia and R. Sun, J. Mater. Sci., 50, 6567 (2015); https://doi.org/10.1007/s10853-015-9194-7.

99. Q. Wang, C. Hu, H. Zhang, Y. Zhang, T. Liu, A. Qian and Q. Xia, J. Microencapsul., 33, 785 (2016); https://doi.org/10.1080/02652048.2016.1264494.

100. S. Tantarawongsa and T. Phaechamud, Thai Pharm. Health Sci. J., 6, 66 (2011).

101. K.P. Parthasarathi, D. Mudit, R. Prudhvi, D. Lavanya and L.N.V. Krishna, Int. Res. J. Pharm., 2, 82 (2011).

102. L. Zhang, L. Zhang, M. Zhang, Y. Pang, Z. Li, A. Zhao and J. Feng, Drug Deliv., 22, 475 (2015); https://doi.org/10.3109/10717544.2013.861659.

103. F.L. Yen, T.H. Wu, L.T. Lin, T.M. Cham and C.C. Lin, Pharm. Res., 26, 893 (2009); https://doi.org/10.1007/s11095-008-9791-0.

104. J. Cui, B. Yu, Y. Zhao, W. Zhu, H. Li, H. Lou and G. Zhai, Int. J. Pharm., 371, 148 (2009); https://doi.org/10.1016/j.ijpharm.2008.12.009.

105. M. Sierant, P. Paluch, M. Florczak, A. Rozanski and B. Miksa, Colloids Surf. B Biointerfaces, 111, 571 (2013); https://doi.org/10.1016/j.colsurfb.2013.07.002.

106. R. Zhou, X. Zhu, G. Hung, N. Zhang and B. Zhang, Sheng Wu Yi Xue Gong Cheng Xue Za Zhi, 24, 918 (2007).

107. J. Khan, A. Alexander, S. Ajazuddin, Saraf and S. Saraf, J. Control. Rel., 168, 50 (2013); https://doi.org/10.1016/j.jconrel.2013.02.025.

108. S. Li, Z. Ji, M. Zou, X. Nie, Y. Shi and G. Cheng, AAPS PharmSciTech, 12, $1011(2011)$ https://doi.org/10.1208/s12249-011-9665-3.

109. L. Wei, G. Li, Y.D. Yan, R. Pradhan, J.O. Kim and Q. Quan, Arch. Pharm. Res., 35, 1037 (2012); https://doi.org/10.1007/s12272-012-0611-z.

110. Q. Cai, L. Liang, Y.P. Huang and S.X. Hou, Zhongguo Zhongyao Zazhi, 32, 2003 (2007)

111. N. Chouhan, V. Mittal, D. Kaushik, A. Khatkar and M. Raina, Curr. Drug Deliv., 12, 244 (2015); https://doi.org/10.2174/1567201811666141021142606. 